\title{
Огнеупорный бетон из отходов Ковдорского ГОКа на магнийфосфатной связке
}

Белогурова О.А., Саварина М.А., Шарай Т.В.

Институт химии и технологии редких элементов и минерального сырья им. И.В. Тананаева КНЦ PAH, Anamumbl, belog_oa@chemy.kolasc.net.ru

Аннотация. Основное направление по совершенствованию производства огнеупоров - развитие технологии неформованных материалов. Наиболее востребованными являются огнеупорные бетоны. Они способны схватываться и твердеть при низких температурах с образованием структур, сохраняющих свои характеристики при нагревании. В этом исследовании бетоны были получены из брикета на основе форстеритового концентрата из отходов Ковдорского горно-обогатительного комбината и связующего фосфата магния. В результате был выбран зерновой состав шихты, найдено соотношение заполнителя и связующего для улучшения структурных свойств бетона; выявлено влияние состава и температуры термообработки брикета на физико-технические свойства полученных материалов. Бетоны обладают следующими характеристиками:

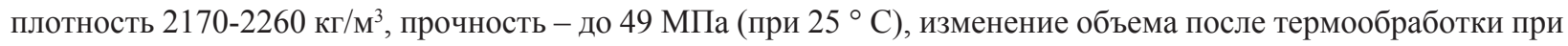
450-1000 ${ }^{\circ}$ С составляет $1-2 \%$.

Ключевые слова: неформованный материал, форстеритовый концентрат, магнийфосфатная связка, огнеупорный бетон.

\section{Refractory concrete from wastes of the Kovdorsky GOK on a magnesium phosphate binder}

\author{
Belogurova O.A., Savarina M.A., Sharai T.V. \\ Tananaev Institute of Chemistry - Subdivision of the Federal Research Centre KSC RAS, Apatity, \\ belog_oa@chemy.kolasc.net.ru
}

\begin{abstract}
The main direction for improving the production of refractories is the development of the unshaped materials technology. The most popular among them are refractory concretes. They are capable of setting and hardening at low temperatures, with the formation of structures that retain their characteristics when heated. In this investigation concretes were obtained from a briquette made of a forsterite concentrate from waste products of the Kovdorsky Mining and Processing Plant and magnesium phosphate binder. As a result of the research, the grain composition of the charge was selected; found the ratio of aggregate and binder to improve the structural properties of concrete; the influence of the composition and temperature of briquette heat treatment on the physical and technical properties of the materials obtained is shown. Concretes possess the following characteristics: density $2170-2260 \mathrm{~kg} / \mathrm{m}^{3}$, strength - up to $49 \mathrm{MPa}\left(\right.$ at $25^{\circ} \mathrm{C}$ ), volume change after heat treatment at $450-1000{ }^{\circ} \mathrm{C}$ is $1-2 \%$.
\end{abstract}

Keywords: unshaped material, forsterite concentrate, magnesium phosphate binder, refractory concrete.

Основное направление совершенствования производства огнеупоров связано с развитием технологии неформованных огнеупоров. В зарубежных странах в общем объеме производимых огнеупоров доля неформованных огнеупоров возрастает, например, в Японии этот показатель вплотную приближается к 70 \%. По данным агентства DISCOVERY Research Group, объем рынка неформованных огнеупоров в России в 2016 г. составил 1140.7 тыс. т, что эквивалентно \$ 418.4 млн. В 2015 г. он равнялся \$ 522 млн. Темп прироста рынка в 2016 г. составил 19.9 \%. С 2013 г. темп прироста этого сегмента рынка положительным не был. Объем импорта неформованных огнеупоров в Россию в 2016 г. составил 176.3 тыс. т. Этот показатель эквивалентен \$ 161.7 млн. Объем экспорта неформованных огнеупоров из России в 2016 г. составил 78.9 тыс. т. Это значение соответствует \$ 20.9 млн.

Наиболее востребованными среди неформованных огнеупоров являются огнеупорные бетоны и торкрет-массы. Огнеупорными бетонами называют безобжиговые композиционные материалы с огнеупорностью от $1580^{\circ} \mathrm{C}$ и выше, состоящие из огнеупорного заполнителя, вяжущего материала, добавок и пор, затвердевающие при нормальной или повышенной температуре и обладающие ограниченной усадкой при температуре применения. 
Перспективным связующим материалом являются фосфатные соединения, которые хорошо зарекомендовали себя в технологии огнеупоров, обеспечивая высокую термостойкость и прочность при высоких температурах (Скурихин В.В. и др., 2004; Кащеев И.Д и др., 2007).

Для фосфатных связок схемы превращений цементирующей части неоднозначны и в композициях присутствуют фазы переменного состава. Новообразования по большей части аморфны и лишь при нагревании склонны к кристаллизации и взаимодействию с зернами наполнителя. Микроструктура подвергается значительным изменениям при термообработке.

Целью исследований являлась разработка технологии огнеупорного бетона из форстеритового концентрата из отходов обогатительного производства Ковдорского ГОКа (Петрик А.И. и др., 2012) с использованием в качестве связующего магнийфосфатной связки.

Химический анализ форстеритового концентрата, мас. \%: $\mathrm{MgO}-43-48 ; \mathrm{SiO}_{2}-33-39$; $\mathrm{FeO}$ - 4.4-5.3; $\mathrm{Fe}_{2} \mathrm{O}_{3}-0.8-5.9 ; \mathrm{CaO}-0.6-2.4 ;$ п.п.п. - 0.1-1.5.

Для уменьшения влияния примесей и повышения огнеупорных свойств материала к форстеритовому концентрату, полученному из отходов обогатительного производства Ковдорского ГОКа, необходимо добавлять оксид магния, в данной работе использован бой магнезитовых изделий. В присутствии последнего не огнеупорные энстатит $\left(1557^{\circ} \mathrm{C}\right)$ и оксид железа переходят в форстерит $\left(1890^{\circ} \mathrm{C}\right)$ и магнезиоферрит $\left(1750^{\circ} \mathrm{C}\right)$ :

В технологии форстеритовых огнеупоров предпочтителен следующий гранулометрический состав шихты: до 55 мас. \% фракции 3-0.63 мм, до 40 мас. \% фракции менее 0.1 мм. Следовательно, для сырого форстеритового концентрата, гранулометрический состав которого находится в диапазоне $<0.2$ мм, требуется брикетирование.

Реактив для получения связки: $\mathrm{mMgCO}_{3} \cdot \mathrm{Mg}(\mathrm{OH})_{2} \cdot \mathrm{nH}_{2} \mathrm{O}$ (магний углекислый основной): $\mathrm{Mg}_{5}\left(\mathrm{CO}_{3}\right)_{4}(\mathrm{OH})_{2} \cdot 4 \mathrm{H}_{2} \mathrm{O}$ :

$$
4 \mathrm{MgCO}_{3} \cdot \mathrm{Mg}(\mathrm{OH})_{2} \cdot 4 \mathrm{H}_{2} \mathrm{O}+10 \mathrm{H}_{3} \mathrm{PO}_{4} \rightarrow 5\left[\mathrm{Mg}\left(\mathrm{H}_{2} \mathrm{PO}_{4}\right)_{2} \cdot 2 \mathrm{H}_{2} \mathrm{O}\right]+4 \mathrm{CO}_{2}
$$

По мнению французских исследователей $\mathrm{Mg}\left(\mathrm{H}_{2} \mathrm{PO}_{4}\right)_{2} \cdot 2 \mathrm{H}_{2} \mathrm{O}$ в диапазоне $90-200^{\circ} \mathrm{C}$ переходит в $\mathrm{Mg}\left(\mathrm{H}_{2} \mathrm{PO}_{4}\right)_{2}$; при $200-350^{\circ} \mathrm{C}$ преобразуется в дигидропирофосфат $\mathrm{MgH}_{2} \mathrm{P}_{2} \mathrm{O}_{7}$, при $400-450^{\circ} \mathrm{C}$ - в аморфный полифосфат $\left(\mathrm{Mg}\left(\mathrm{PO}_{3}\right)_{2}\right)_{\mathrm{n}}$, при $500-800^{\circ} \mathrm{C}$ наблюдается переход этого соединения в тетраметафосфат $\mathrm{Mg}_{2} \mathrm{P}_{4} \mathrm{O}_{12}$ (Soudee E., 1999).

В работе японских ученых (Makio Kinoshita et al., 1982) приводятся данные по возможным преобразованиям фосфатов:

$\mathrm{Mg}\left(\mathrm{H}_{2} \mathrm{PO}_{4}\right)_{2} \cdot 2 \mathrm{H}_{2} \mathrm{O} \rightarrow \mathrm{Mg}\left(\mathrm{H}_{2} \mathrm{PO}_{4}\right)_{2} \rightarrow \mathrm{MgH}_{2} \mathrm{P}_{2} \mathrm{O}_{7} \rightarrow \mathrm{Mg}_{2} \mathrm{P}_{4} \mathrm{O}_{12}$ ( при 95,240 и $435^{\circ} \mathrm{C}$ соответственно)

$\mathrm{Mg}\left(\mathrm{H}_{2} \mathrm{PO}_{4}\right)_{2} \cdot 2 \mathrm{H}_{2} \mathrm{O} \rightarrow \mathrm{Mg}\left(\mathrm{H}_{2} \mathrm{PO}_{4}\right)_{2} \rightarrow \mathrm{MgH}_{2} \mathrm{P}_{2} \mathrm{O}_{7}+$ аморфная фаза $\rightarrow \mathrm{Mg}_{2} \mathrm{P}_{4} \mathrm{O}_{12}$ (при 110, 240 и $430-650^{\circ} \mathrm{C}$ соответственно).

Взаимодействие форстерита и составляющих фосфатной связки изучено Хорошавиным Л.Б. (1990):

$$
\begin{aligned}
& \mathrm{Mg}_{2} \mathrm{SiO}_{4}+2 \mathrm{H}_{3} \mathrm{PO}_{4}+4 \mathrm{H}_{2} \mathrm{O} \rightarrow 2\left(\mathrm{MgHPO}_{4} \cdot 3 \mathrm{H}_{2} \mathrm{O}\right)+\mathrm{SiO}_{2} \\
& 2\left(\mathrm{MgHPO}_{4} \cdot 3 \mathrm{H}_{2} \mathrm{O}\right) \rightarrow \mathrm{Mg}_{2} \mathrm{P}_{2} \mathrm{O}_{7}+7 \mathrm{H}_{2} \mathrm{O} \\
& 2 \mathrm{Mg}_{2} \mathrm{SiO}_{4}+\mathrm{Mg}_{2} \mathrm{P}_{2} \mathrm{O}_{7}+\mathrm{SiO}_{2} \rightarrow \mathrm{Mg}_{3}\left(\mathrm{PO}_{4}\right)_{2}+3 \mathrm{MgSiO}_{3} \\
& 3 \mathrm{Mg}_{2} \mathrm{SiO}_{4}+2 \mathrm{H}_{3} \mathrm{PO}_{4} \rightarrow \mathrm{Mg}_{3}\left(\mathrm{PO}_{4}\right)_{2}+3 \mathrm{MgSiO}_{3}+3 \mathrm{H}_{2} \mathrm{O}
\end{aligned}
$$

В данном исследовании использованы брикеты следующих составов: №8 - 60 \% фр. $<0.2$ мм и $15 \%$ фр. $<0.063$ мм форстеритового концентрата и $25 \%$ боя магнезитовых изделий фр. 3-0.2 мм; № $8.1-50 \%$ фр. $<0.2$ мм и $15 \%$ фр. $<0.063$ мм форстеритового концентрата и $35 \%$ боя магнезитовых изделий фр. 3-0.2 мм. Температура обжига брикета: 1300 и $1400^{\circ} \mathrm{C}$.

Для получения зависимости показателей бетона от количества тонкой фракции брикетов 8 и 8.1 в шихте использовали следующие соотношения - $80 \%$ фр. $<3$ мм и $20 \%<0.063$ мм; $70 \%<$ 3 мм и $30 \%<0.063$ мм; $60 \%<3$ мм и $40 \%<0.063$ мм; $50 \%<3$ мм и $50 \%<0.063$ мм. Диапазон термообработки бетона - от 25 до $1200^{\circ} \mathrm{C}$. Были построены графики изменения показателей плотности, изменения объема и прочности бетонов в зависимости от вида используемого брикета и фракционного состава шихты (рис. 1, 2). 

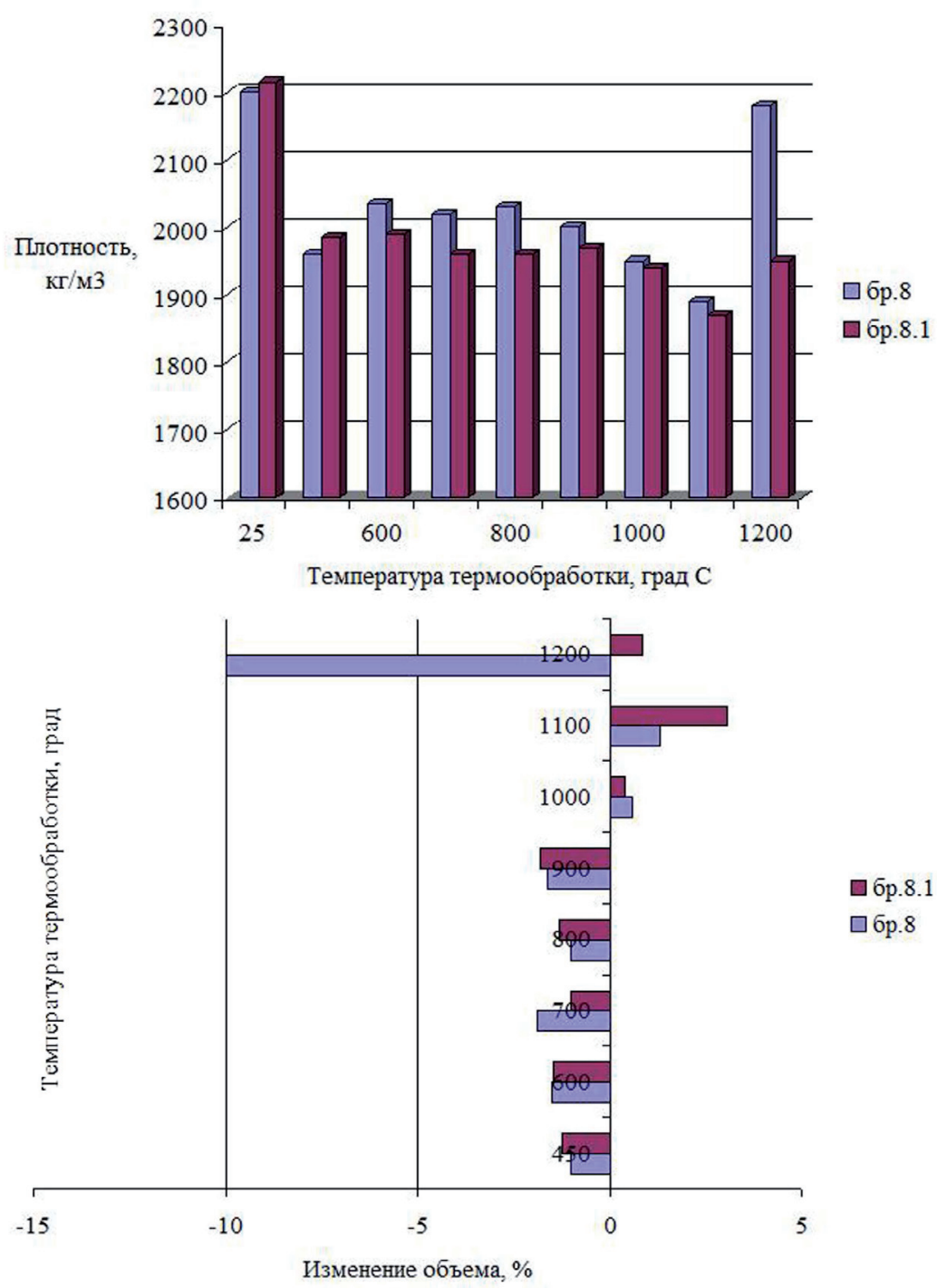

$\square 6 \mathrm{p} .8$

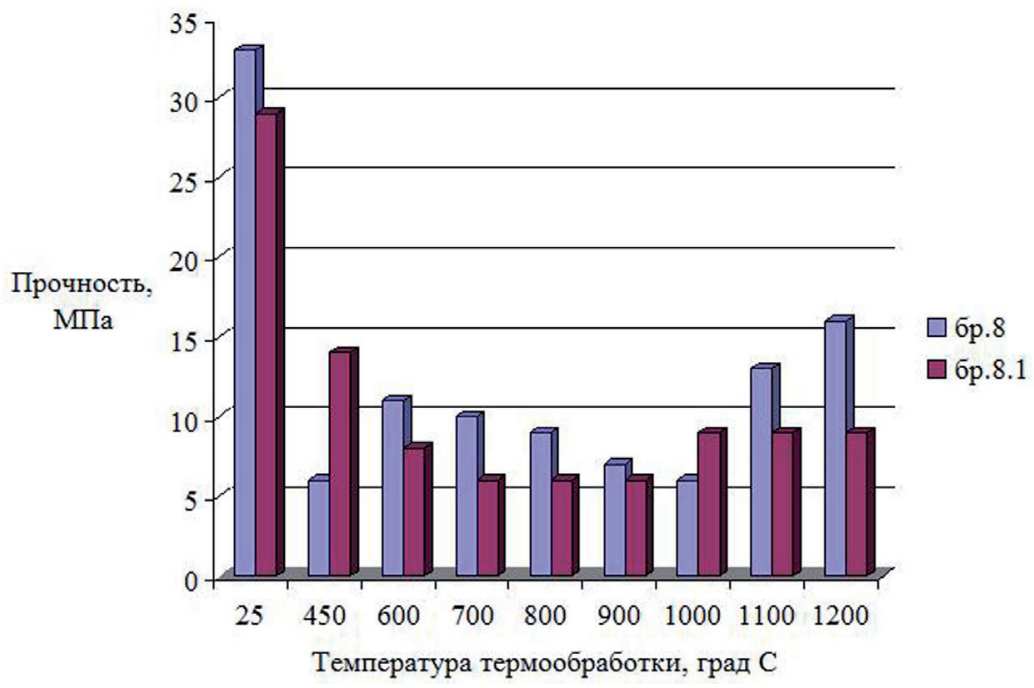

В легенде номера брикетов, обожженных при $1400^{\circ} \mathrm{C}$.

Состав шихты: 70 \% фракции $<3$ мм и $30 \%$ фракции $<0.063$ мм.

Рис. 1. Зависимость показателей свойств бетона от состава брикета и температуры термообработки.

The legend indicates numbers of the briquettes calcined at $1400^{\circ} \mathrm{C}$.

Charge composition: $70 \%$ fraction $<3 \mathrm{~mm}$ and $30 \%$ fraction $<0.063 \mathrm{~mm}$.

Fig. 1. Dependence of concrete properties from the composition of the briquette and the temperature of heat treatment. 

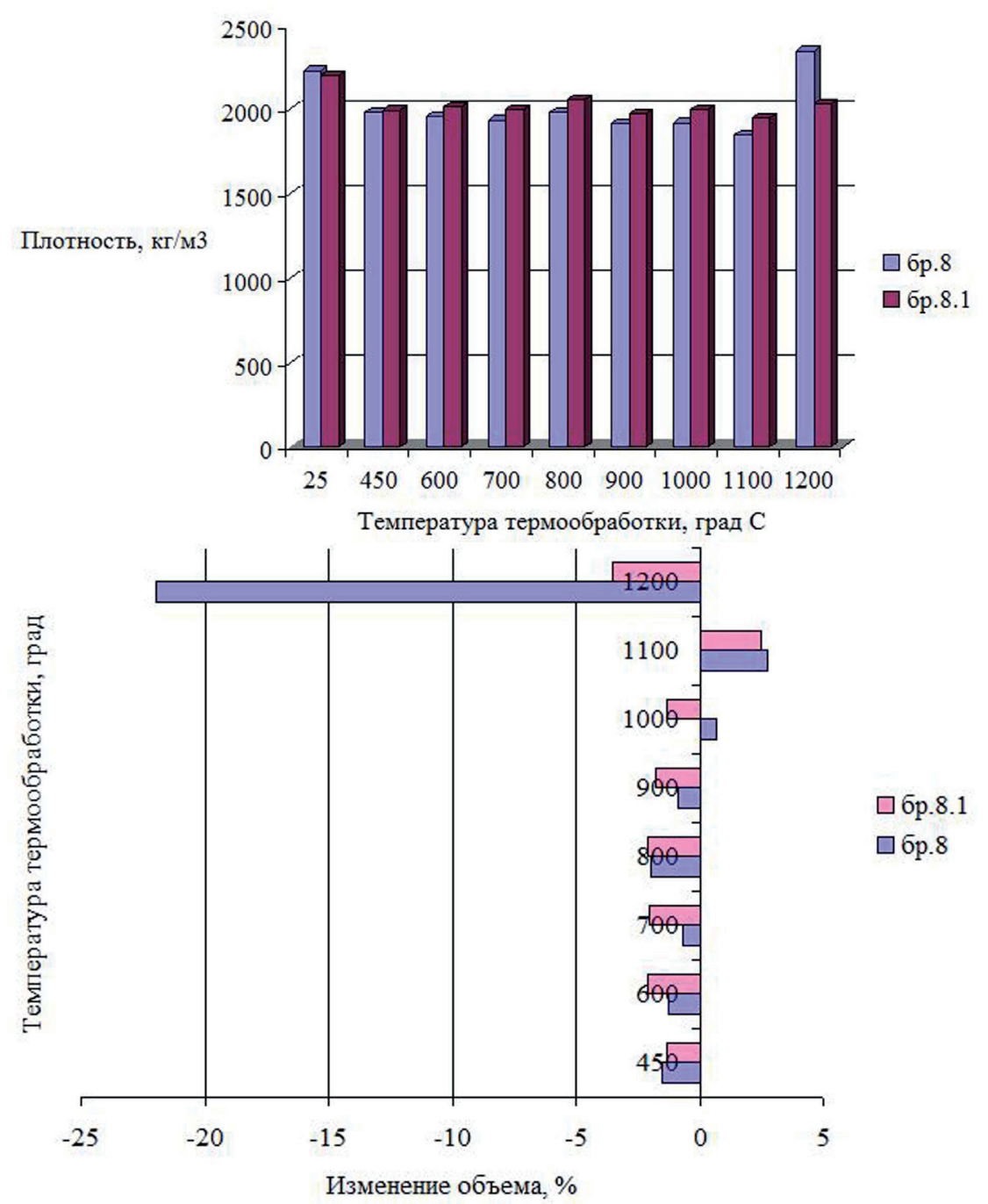

$\square 6 \mathrm{p} .8 .1$

$\square 6 \mathrm{p} .8$

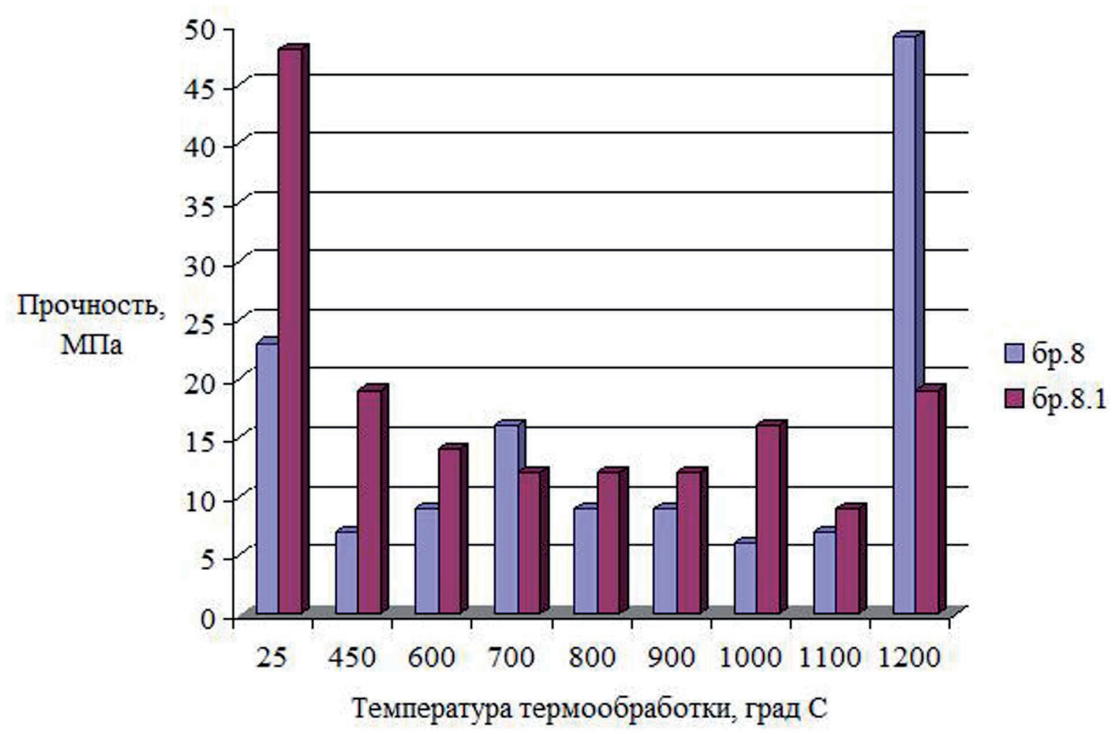

В легенде номера брикетов, обожженных при $1400^{\circ} \mathrm{C}$.

Состав шихты: $60 \%$ фракции $<3$ мм и $40 \%$ фракции $<0.063$ мм.

Рис. 2. Зависимость показателей свойств бетона от состава брикета и температуры термообработки.

The legend indicates numbers of the briquettes calcined at $1400^{\circ} \mathrm{C}$.

Charge composition: $60 \%$ fraction $<3 \mathrm{~mm}$ and $40 \%$ fraction $<0.063 \mathrm{~mm}$.

Fig. 2. Dependence of concrete properties from the composition of the briquette and the temperature of heat treatment. 
В результате исследований подобран зерновой состав шихты с целью максимального заполнения объема; найдено соотношение заполнителя и связующего для повышения конструкционных свойств бетона; показано влияние состава и температуры термообработки брикета на физикотехнические свойства получаемых материалов.

Более высокими показателями свойств обладает бетон на основе брикета, а не сырого форстеритового концентрата. Например, установлено, что при комнатной температуре указанные бетоны имеют следующие характеристики: плотность - 2230 и 1280-1450 кг $/ \mathrm{M}^{3}$, прочность - 12.0 и 1.2-1.5 МПа соответственно. После термообработки при $450{ }^{\circ} \mathrm{C}$ : плотность -2060 и $1310 \mathrm{\kappa г} / \mathrm{M}^{3}$, прочность - 15 и 0.8 МПа соответственно.

Температура первоначального обжига брикета влияет на показатель изменения объема после термообработки в диапазоне $600-1000^{\circ} \mathrm{C}$. Для образцов из брикета, обожженного при $1300^{\circ} \mathrm{C}$, его значение $1.8 \%$, тогда как для образцов из брикета, обожженного при $1400{ }^{\circ} \mathrm{C}-0.5 \%$.

Бетон из брикета с содержанием 25 мас. \% боя магнезитовых изделий в большей степени спекается при температуре $1200^{\circ} \mathrm{C}$, чем из брикета, содержащего 35 мас. $\%$ боя магнезитовых изделий. Изменение объема в первом случае достигает $22 \%$, во втором $-3.6 \%$.

В состав шихты для бетона из брикета, содержащего 25 мас. \% боя магнезитовых изделий рекомендуется вводить от 20 до 30 мас. \% фракции менее 0.063 мм, так как при большем ее количестве увеличиваются объемные изменения при $1100{ }^{\circ} \mathrm{C}$ и происходит резкий скачок спекания при $1200{ }^{\circ} \mathrm{C}$. Шихта для получения бетона из брикета, содержащего 35 мас. \% боя магнезитовых изделий, должна содержать до $40 \%$ фракции менее 0.063 мм, так как в этом случае получены высокие показатели прочности и плотности и уменьшение объема при $1200^{\circ} \mathrm{C}$ не так резко выражено.

На основе брикета 8.1 получены бетоны со следующими характеристиками: плотность

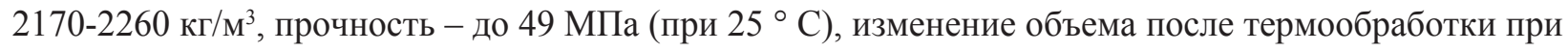
450-1000 ${ }^{\circ}$ С составляет $1-2 \%$.

Таким образом, в результате исследования подобран зерновой состав шихты с целью максимального заполнения объема; найдено соотношение заполнителя и связующего для повышения конструкционных свойств бетона; показано влияние состава и температуры термообработки брикета на физико-технические свойства получаемых материалов.

Работа выполнена в рамках темы НИР №0230-2018-0007.

\section{Литература}

1. Кащеев И.Д., Стрелов К.К., Мамыкин П.С. Химическая технология огнеупоров: учебное пособие. М.: Интермет Инжиринг. 2007. 752 c.

2. Kinoshita M., Itatani K., Kishioka A. Thermal analysis of $\mathrm{Mg}\left(\mathrm{H}_{2} \mathrm{PO}_{4}\right)_{2} \cdot 2 \mathrm{H}_{2} \mathrm{O}$ under various reduced pressures // Gypsum and Lime. 1982. V. 177. P. 13-19.

3. Петрик А.И., Быховец А.Н., Сохарев В.А., Переин В.Н., Сердюков А.П. Модернизация минеральносырьевой базы в стратегии долгосрочного развития Ковдорского ГОКа // Горный журнал. 2012. № 10. C. $12-17$.

4. Скурихин В.В., Ермаков И.Н. Традиционные и новые огнеупорные материалы для строительства и ремонта стекловаренных печей // Стекло и керамика. 2004. № 10. С. 36-39.

5. Soudee E. Liants phosphomagnesiens - mecaniqme de prise et durabilite: diss. Doctorat.- Lyon. 1999. 266 p.

6. Хорошавин Л.Б. Магнезиальные бетоны. М.: Металлургия, 1990. 168 с. 